\title{
Science and the Necessity of Faith: Notes on "Appendix to the Transcendental Dialectic"
}

\author{
Min Seong Kim ${ }^{1}$ \\ ${ }^{1}$ Graduate Program in Cultural Studies, Sanata Dharma University, Yogyakarta, Indonesia \\ E-mail: minseong.kim@usd.ac.id ${ }^{1}$
}

\begin{abstract}
Apropos Kant's discussion of scientific practice in the section of the first Critique entitled "Appendix to the Transcendental Dialectic," there has long been a tendency in Anglophone Kant scholarship to downplay the role of God or quickly brush aside the centrality of the idea in the Kantian system. As a way of setting the stage for evaluating the place of God in Kant's philosophy, this paper, in a concise and straightforward manner, attempts to make the connection between science and the idea of God as it appears in the first Critique explicit and explain why Kant is driven to make that connection. In the first half of the paper, I summarize Kant's discussion of scientific practice as presented in the first part of the Appendix, followed by a brief discussion of a problem his account raises. In the second half of the paper, I elaborate the connection between science and God as a response to that problem.
\end{abstract}

Keyword: Kant, God, idea of reason, scientific practice, unity of nature

\section{Introduction}

Apropos Kant's discussion of scientific practice in the section of the first Critique entitled "Appendix to the Transcendental Dialectic," there has long been a tendency in Anglophone Kant scholarship to downplay the role of God or quickly brush aside the centrality of the idea in the Kantian system. Thomas Wartenberg's (1992) seminal essay on Kant's account of science in Critique of Pure Reason does not mention God or the highest intelligence at any length. Neither does Michelle Grier (2001) make the connection between scientific practice and God explicit in her important study of transcendental illusion, Kant's Doctrine of Transcendental Illusion. This underlying cause of this tendency no doubt has some in common with that which underpins the popularity of post-metaphysical readings of Kant and post-Kantian German Idealism, especially within Anglophone scholarship (see Pinkard, 2002; Sandkaulen, 2012). But regardless of the kind of assessment apropos Kant's evocation of God or the value of post-metaphysical readings one might finally reach, no accurate understanding of Kant's views on scientific practice can be made without understanding the rationale for his evocation of the "being of highest intelligence" in the Appendix. The aim of this paper is to, in a concise and straightforward manner, make the connection between science and the idea of God as it appears in the first Critique explicit and explain why Kant is driven to make that connection. In the first half of the paper, I summarize Kant's discussion of scientific practice as presented in the first part of the Appendix, followed by a brief discussion of a problem his account raises. In the second half of the paper, I elaborate the connection between science and God as a response to that problem.

\section{Heuristic of Scientific Practice and its Problem}

An idea of pure reason, in spite of being an illusion (Schein) generated by reason, can nonetheless have legitimate theoretical use. This is, it might be argued, one of the senses in which Kant redefines metaphysics without destroying it. In science, understanding (Verstand) produces concepts to which objects of experience conform, while reason seeks to systematize concepts of understanding. Why understanding alone cannot suffice for scientific enquiry, thus is in need of reason, is made evident when it is recalled that understanding cannot by itself decide when, where, and for what purpose it should apply itself. As Susan Neiman writes, the operations of understanding are "routine, automatic, and mechanical" (Neiman, 1997, p. 48). A mode of enquiry that can properly be called "scientific" requires reason, which can apply itself freely and purposefully, to guide the purposive application of understanding. Reason, in this respect, provides direction to scientific enquiry (A665/B693-A666/B694), which is driven, as it were, by two horses: through understanding, science generates concepts that take account of the diversity of empirical experience, and under the guidance of reason, science strives to brings itself into a 
systematic unity, that is, a coherent body of knowledge-and this idea of systematic unity is to serve a regulative role. Such a role, for Kant, is the only legitimate employment of ideas of pure reason.

It is possible to identify three functions of reason in scientific enquiry that follow from the idea of systematic unity. First, reason assists in the systematization of scientific knowledge through following principles: specificity, which is the maximization of diversity and the particular laws that apply to particular kinds of phenomena; homogeneity, which involves the subsumption of particular concepts and principles under general, higher-order concepts and laws whose explanatory scope, presumably, extend over more diverse phenomena; and affinity or continuity, which involves providing a logical ordering all concepts that stand in between higher-order concepts and lower-order concepts (A657/B685-A658/B686). Reason is to scientific enquiry as a taxonomy is to zoology. Second, reason plays a role in the formation of scientific constructs or idealizations which are indispensable for articulating theories and constructing of experimental hypotheses. Kant writes:

By general admission, pure earth, pure water, pure air, etc. are not to be found. We require, however, concepts of them [...] in order properly to determine the share which each of these natural causes has in producing appearances. [...] the influence of reason on the classifications of the natural scientist is still easily detected. (A646/B674)

While it might sound somewhat quaint to modern ears, Kant's reasoning here is nonetheless based on some intuitive and practical considerations. If there was no concept of "pure water," one would not be able to examine and speak of the degree to which actual rivers and streams are polluted. Without a concept comparable to "pure air," it would not be possible to conceive, say, the formulae of ideal gas. Since objects of scientific idealizations as such are not objects of any possible experience, it is not up to understanding alone but reason to generate these abstractions, which can then be used to formulate and legitimately express theories, hypotheses, and laws of nature. When Kant asserts that "these concepts of reason are not derived from nature" but that "we interrogate nature in accordance with these ideas, and consider our knowledge as defective so long as it is not adequate to them" (A645/B673), his view seems to be in accordance with a certain widespread conception of science, wherein the formulation of hypotheses are followed by experiments on the basis of those hypotheses. Third, the idea of systematic unity implies that scientific enquiry is premised on the assumption that higher-order principles are available. The example Kant uses to illustrate the use of such highest principle is the case of causal powers. Since there are multiplicities of ways in which a thing may interact with other things, it might first appear as if there are diverse kinds of causal powers. Scientific enquiry seeks to discover, according to Kant, the "hidden identity" of the seemingly diverse manifestations of causal powers. It is, in other words, oriented towards the search for an increasingly more "fundamental power" that underlies manifestations of particular causal-effect phenomena (A649/677). A simple example: since jet aircrafts and helicopters seemingly employ different kinds of mechanisms in order to fly, it may first appear that there are different kinds of causal powers at work. Guided by the purpose of discerning a higher-order causal power that encompasses both kinds of apparently different causal powers, science attains the concept of lift. Hence, science operating with the aim of systematicity subsumes apparently different manifestation of causal powers underlying the flight of a jet aircraft and that of a helicopter under a broader concept. Reason seeks to ultimately discern, according to Kant, a single "absolutely fundamental" power, and discerning such a fundamental power is the goal toward which a theoretical use of reason strives. Crucially, however, that the goal is one which reason strives does not entail the goal is achievable: there is no guarantee that such higher powers or principles will actually be found. Hence, "one asserts not that such a power must in fact be found, but rather that one must seek it for the benefit of reason" (A650/B678). The familiar but critical Kantian distinction is pertinent: reason's role is regulative, not constitutive.

In a statement that truly befits the forerunner of German Idealism, Kant asserts that reason, with its idea of systematic unity, aspires for a body of scientific knowledge which is not a "contingent aggregate," but rather a "system interconnected in accordance with necessary laws" (A646/B674). While the notion of "necessary laws" of nature are not fully explicated in the Appendix, the aforementioned three functions of reason in scientific enquiry all strive toward the same idea. Had this been all Kant says about science, however, the result of would be a rather mundane account of what a scientific enquiry is. If the idea of systematic unity of knowledge is taken simply to be a rule that serves to guide scientific enquiry in general, that is, a subjective 
maxim whose assumption, either tacit or explicit, is discernible in what any practice that can be regarded as "scientific," then the idea of systematic unity would not carry with it any substantive metaphysical commitment, since it would simply be a heuristic that is followed for purely pragmatic purposes. A well-known example of such a purely pragmatic strategy is Daniel Dennett's (1989) intentional strategy, in which ascriptions of mental states can be made independently of any metaphysical commitment. For Dennett, the reality of mental life of the thing that is taken to be a rational agent, in so far as the attribution of rational agency and subsequent intentional states prove to be useful as a predictive and explanatory strategy. The idea of systematic unity as a heuristic, similarly, would be a useful way of going about doing science. But to assert that the unity is in any sense an accurate reflection of reality would be an instance of a constitutive use of the idea, which must be deemed illegitimate according to the Kantian proscription against speculative metaphysics (see Willaschek, 2018, Chapter 9).

While the pragmatic view explained above of the role of systematic unity in science certainly captures one aspect of the Kantian proposal in the Appendix, it cannot be the entirety of Kant's story, given that the faculty of reason, for him, is one that is characterized by a need to reach the unconditioned. The implication of such a natural and irresistible tendency in reason is that reason would remain unsatisfied until it reaches an ultimate explanation that explains every level of "conditioned" on the basis of some higher condition, until it reaches a point where the question of why can no longer be asked. The predicament of reason is depicted as follows by Kant:

[Reason seeks] somewhere for a resting place in the regress from the conditioned, which is given, to the unconditioned, which in itself and as regards mere concept is not indeed actually given, but which alone can complete series of conditions carried out to the grounds. Now this is the natural course taken by every human reason, even the most common. [...] It begins not with concepts, but with common experience, and thus grounds itself on something existing. But this footing gives way unless it rests on the immovable rock of the absolutely necessary. But this itself floats without a support if there is still only empty space outside it and under it, unless it itself fills everything so that no room is left over for any further Why?-i.e., unless it is infinite in its reality. (A584/B612)

Reason cannot rest until it attains "the concept of which contains within itself the "Because' to every 'Why?'” (A585/B613). Even if the practice of science guided by the idea of systematic unity worked, and Kant was well aware of how successful an enterprise natural science had become by his time, that alone would not satisfy reason. For a demand would then emerge from within reason itself, which returns reason to a path of restlessness before an explanation as to why scientific practice works were found. Reason demands answers to questions such as: How is it possible that we are in fact able to attain some level of systematic unity in our knowledge about nature? Do the laws that are identified by scientific practice really accord to the laws of nature?

To further highlight the point, it is instructive to return to the earlier example of Dennett's intentional strategy. Dennett does begin to provide an explanation of why the intentional strategy works, at least when it is applied to human behavior. The gist of Dennett's explanation as to why intentional strategy works consists of the claim that human beings have evolved so that they realize rational agency. It follows that the ascription of intentional states to human beings based on an ideal model of rational agency would, in many cases, satisfactorily function as a predictive and explanatory strategy. It will be clear, however, that there is no analogue to the reductive explanation which Dennett provides when the question being raised pertains to the viability of scientific enquiry per se. A response to the demand of reason cannot make recourse to a subvenient level of "reality" as in Dennett, for that underlying reality in the Dennett-style reductive explanation is none other than nature, which is but the very object of scientific enquiry. The problem that Kant articulates, however, is one that concerns the very possibility of scientific enquiry as such, which prohibits a solution that relies on the concept of nature (or reality) as an object of possible experience. The answer to the demand of reason neither could nor should be aimed at showing that the heuristic is a derivative mode of engaging with the natural world whose success is grounded on some underlying reality. It has to be aimed, rather, at offering a convincing explanation as to why it is legitimate to continue to have faith in the success of the heuristic. 


\section{The Unconditioned Condition of Scientific Practice}

The exposition in this section shall proceed according to the logical progression of the Appendix, which can be laid down as follows:

a. The idea of the systematic unity as a heuristic is indispensable.

b. If scientific enquiry based on the idea of systematic unity is successful, if must be the case that nature is such that it is amenable to the idea of systematic unity.

c. Hence, nature itself is systematically unified.

d. (3) is not demonstrable; it can only be presupposed. If (3) were demonstrable, the systematic unity of nature would be constitutive, not regulative-but this is not the case.

e. We can think of a condition under which (3) would obtain.

f. Whatever result gained from the consideration of (5), we may continue to believe in it, in order to justify our scientific practice which is based on (1). This is to say that it is legitimate to believe in the results of (5). Consequently, it is also legitimate to presuppose (3), in so far as (3) is necessary for science.

Kant claims that the idea of systematic unity is not merely a heuristic, but a necessary presupposition; and systematic unity is not just the shape that the body of our knowledge must endeavor to attain, since that would make the idea of systematic unity merely subjective. His claim is that nature itself must be presupposed to be amenable to the systematic unity which is sought by reason:

One might have believed that this is merely a device of reason for achieving economy, for saving as much trouble as possible, and a hypothetical attempt that, if it succeeds, will through the unity give probability to the grounds of explanation it presupposed. Yet such a selfish aim can easily be distinguished from the idea, in accordance with which everyone presupposes that this unity of reason conforms to nature itself; and here reason does not beg but commands, though without being able to determine the bounds of this unity. (A653/B681)

As Paul Guyer $(2003,2005)$ explains, Kant holds that if nature could not be seen as systematic, then-in Kant's words-"reason would proceed directly contrary to its vocation since it would set as its goal an idea that entirely contradicts the arrangement of nature" (A653/B681). Even though the proposition that nature is in fact amenable to the idea of systematic unity of human knowledge is an indemonstrable proposition (point (4)), the systematic unity of nature must be assumed (point (3)). It cannot be arbitrarily posited that nature's systematic unity is harmonious to the systematic unity in human knowledge, as such an arbitrary positing would constitute a case of economic contrivance. Rather, an account is needed whereby it is explained why it is legitimate to presuppose, even without demonstrable evidence, systematic unity as inherent in nature. The Kantian explanation for that legitimacy is a pragmatic one, familiar to readers of his practical philosophy.

A transcendental principle must be presupposed, Kant asserts, "whereby such a systematic unity is a priori assumed to be necessarily inherent in the objects.... we have to presuppose the systematic unity of nature as objectively valid and necessary" (A651/B679). Reason is a voracious faculty whose search for the unconditioned would not cease until it finds a satisfactory explanation. The demand for the justifiability of the assumption of the systematic unity of nature is, therefore, is issued by reason itself, and a transcendental principle, here, the assumption of the systematic unity of nature, is but a means to conceive of a way in which it could be appeased. If reason is appeased thereby, then that suffices to serve as the ground for employing that transcendental principle, in as much as the transcendental principle is such that only by assuming it can reason find satisfaction. For in that case, the principle becomes one of practical necessity, hence one that cannot but be assumed irrespective of the (im)possibility of its alternative grounding. This is the point made in the following passage:

For if the greatest possible empirical use of my reason is grounded on an idea (that of systematic complete unity...), which in itself can never be presented adequately in experience, even though it is unavoidably in experience, even though it is unavoidably necessary for approximating to be highest possible degree of empirical unity, then I am not only warranted but even compelled to realize this idea, i.e., to posit for it an actual object, but only as a Something in general with which I am not acquainted at all and to which, as a ground of that systematic unity and in relation to that, I give such properties as are analogous to the concepts of the understanding in their empirical use. (A677/B705-A678/B706; italics added)

It is at this crucial juncture in the Appendix that the figure of God enters, in order to explain how systematic unity, whose presupposition is necessitated and yet can never be a possible object of experience, can nonetheless be speculated as a possible object of understanding. Kant's 
claim is that the empirical use of human reason-in scientific practice, in this case-induces a practical necessity of positing something, a being. Such a being, Kant suggests, is one that possesses the faculties analogous to those of the human being, but one who can nonetheless behold the world in its totality. This is to say that the world, in its totality, can be an object of understanding for such a being. But if something is an object of that kind for this being, it implies that the object is unified in the understanding of that being. Hence, the positing of this being for whom the totality of the world is an object is equivalent to positing the unity of nature as a whole.

All that is needed for the pragmatic proposal to be workable is to be able to think without contradiction the possibility of the totality of the world, or "world-whole," being an object for the being possessing the highest intelligence. Though such a being, Kant admits, remains "incomprehensible" for us, such a being can nonetheless be posited without contradiction. This positing then allows human faculties to be redescribed as "weak copies" of the faculties of that being, whose faculty of understanding is analogous to that of the human but unlimited, in such a way that the world-whole itself would be an object for it. Thus, Kant writes:

...according to the analogy of realities in the world, of substances, causality, and necessity, I will think of a being that possesses all of these in their highest perfection, and since this idea rests merely on my reason, I am able to think this being as self-sufficient reason, which is the cause of the world-whole through ideas of the greatest harmony and unity; thus I leave out all conditions limiting the idea, so as-under the auspices of such an original ground-to make possible systematic unity of the manifold in the world-whole and, by means of this unity, the greatest possible empirical use of reason, by seeing all combinations as if they were ordained by a highest reason of which our reason is only a weak copy. (A678/B706)

It is the finitude of the human faculties that leaves room to posit a being unrestrained by that quintessential imperfection of any created being-this, incidentally, being the gesture of negative theology, a gesture which some Lacanian analysts would regard as that of clamoring for a "retroactive illusion" of fullness (or perfection) owing to the experience of lack (Fink, 1996; Stavrakakis, 2007). But still, it should not be forgotten, as Kant cautions, that this being of highest intelligence is "a mere idea," one whose

objective reality is not to consist in the fact that it relates straightway to an object [...]; rather, it is only a schema, ordered in accordance with the conditions of the greatest unity of reason, for the concept of a thing in general, which serves only to preserve the greatest systematic unity in the empirical use of our reason, in that one derives the object of experience, as it were, from the imagined object of this idea as its ground or cause. (A670/B698A671/B699)

While a being of highest intelligence may be posited, its being is grounded "only in the idea and not in itself, hence only in order to express the systematic unity which is to serve us as the standard for the empirical use of reason, without settling anything about what the ground of this unity is, or about the inner property of such a being on which, as cause, it rests" (A675/B703). There is a need to posit a being of highest intelligence, but in positing this being, what is not asserted is what this being is really like. Rather, the positing is that of extrapolating from the finitude of human faculties - that our faculties are unable to behold the world in its totality, thereby ascertaining that nature itself is systematically unified-what that being should be like, so that positing this being could alleviate our skepticism about the success of our scientific practice, which must, as Kant sees it, rely on the presupposition of a systematic unity of nature.

For all the limits that Kant has placed on reason, he acknowledges that "the speculative interest of reason," which "makes it necessary to regard every ordinance in the world as if it had sprouted from the intention of a highest reason" (A686/B714), is one that needs to be satisfied. The consequent regulative use of the idea of this being permits us to "consider every connection in the world according to principles of a systematic unity, hence as if they had all arisen from one single all-encompassing being, as supreme and all-sufficient cause" (A686/B714). But nothing that has been said by Kant entails a commitment to the metaphysical thesis that nature in fact is a work of the being of highest intelligence. Rather, what Kant has shown is that there is nothing that prevents the human mind from thinking such a highest intelligence, and that it is in fact necessary to posit such a being of highest intelligence in order to legitimatize and buttress the scientific practice of finite beings that human begins are. As finite beings, we cannot but presuppose that nature itself is amenable to systematic unity, even in the absence of proof. That 
nature conforms to the goal toward which our reason must strive in human scientific practicethis is, for Kant, the inviolable presupposition of scientific practice, or more precisely, a necessary illusion to which reason, by its own appetite, leads us to "direct every empirical use of our reason in its greatest extension as if the objects themselves had arisen from that original image of all reason" (A672/B700).

Reason finds the unconditioned in the highest intelligence, that is, God, who Kant argues is implicit in the presupposition of the unity of nature, a presupposition that is practically necessitated. Yet, God within the Kantian architecture is, to put it straightforwardly, an unconditioned that is necessitated by reason to serve its interests, for it to be able to erect a model for the legitimate use of finite human faculties in the production of scientific knowledge of nature. Kant puts it as follows: "It is not from a highest intelligence that we derive the order of the world in its systematic unity, but rather it is from the idea of a most wise cause that we take the rule that reason is best off using for its own satisfaction when it connects up causes and effects in the world" (A673/B701). It would thus not be entirely erroneous to say that God is an anthropomorphic projection, as God is posited as a being that possesses understanding and reason analogous to those of the human, though in way that is unlimited and in highest perfection such that the worldwhole is an object of understanding for him. It is a mistake, in other words, to assert that the systematic unity in nature comes from God. Nothing that has been said by Kant warrants such a claim, which hypostasizes an idea posited by reason. Instead, can be legitimately said this: human beings are able to comprehend the systematic unity of nature because they can conceive of a condition that would make the systematic unity of nature comprehensible for them, and that "God" designates what is thought as that condition. God is in this sense ens rationis ratiocinatae (a being of reason).

The problem with which Kant is engaged is none other than of establishing the condition of possibility of empirical knowledge. As such, it is one that is not alien to a wide array of philosophical traditions. The French Structuralist Marxism of the 1960s is a good example, as the problem encountered by the idea of systematic unity taken purely pragmatically as a subjective maxim closely resembles the problem confronted by Louis Althusser's commitment to the scientificity of historical materialism. Althusser $(2005 ; 1970)$ claimed that theoretical objects are internal to a particular science, and a particular science produces knowledge according to its own internal criteria. This implies that knowledge produced through the practice of a particular science cannot immediately be identified with knowledge of "reality" or knowledge of a "real" object. At some point, it must be possible to establish a correspondence between a scientific knowledge and the real-otherwise, the entire "scientific Marxism" postulated by Althusser would be a castle built on sand. And yet, a number of well-known critical commentators, including Gregory Elliot (2006) and Peter Dews (1994), have been keen to point out that Althusser could not avoid either circularity or obscurity on this issue. If the critics are right, then the Althusserian theory of knowledge is founded on a leap of faith-a faith in the mysterious homology between the knowledge produced by a scientific practice and reality as such.

Faith, indeed, of an epistemic kind, seems to underpin the most straightforward, naïve form of scientific realism. Such a realism contends that the objects of science do correspond to objects as they really are, and that laws of science do express the laws of nature as they really are. Such a realism would not conform to the restrictions established by Kant's transcendental philosophy (that Kantianism cannot accept the literality of scientific propositions, of course, may be regarded as the problem with the former for someone who shares the "speculative materialist" intuition of Meillassoux [2010]), but what is clear is that such a scientific realism would not be capable of explaining the correspondence between theory and reality. In the absence of an explanation, it would be purely out of luck that human beings are capable of devising intricate theories about reality as such, with the question of why is it that the human mind has been allowed this happy contingency, as well as the Humean one of what sanctions us to continue to believe that luck will serve us well, rendered unanswerable. The practice of scientific enquiry, in the last instance, relies on a faith, namely the faith that good scientific theories will have actual predictive power and that nature as such is comprehensible for us. It may, of course, be possible for practitioners of science to choose to ignore the metaphysical conundrum of the correspondence between nature and mind, and to regard the practice as "useful" in as much as it remains successful in making predictions. However, to turn away from the metaphysical question, Kant believes, would not satisfy reason. It is very much possible that the strength of the Kantian account might not so much lie in the sophistication of its positive content but owes to the insufficient degree to which other 
accounts of the relation between science and reality (or nature) satisfies the demand of reason for the unconditioned, for some final explanation.

\section{Conclusion}

Kant's invocation of God in the context of science is an attempt to convince us, minimally, that we are allowed to have faith in the success of our scientific practice, while at time same time satiating reason's demand for some ultimate answer to the question of why. And the nature of the answer given by Kant, a philosopher whose self-description of his own philosophical outcome is that of "[denying] knowledge to make room for faith" (B xxx), is the outcome of his attempt to negotiate a fragile truce between science and religion. But as European intellectual history after Kant would indicate, his limitation on knowledge failed to satisfy science and the room he secured for faith was not spacious enough for the faithful. In the introduction to the first Critique, Kant remarks that metaphysics is a "battlefield' of "endless controversies" (A viii). The roadblocks and stop signs he placed on the route to metaphysical speculation so as to strike a perpetual peace could not stand permanently. That Kant did not realize this is indicative of his ahistoricism. Reason's demands and the object which satisfies reason are not eternally fixed, for history shapes its demands and determines the object in which it finds satisfaction-a point that would be explored by the greatest of the German Idealists, G. W. H. Hegel (1979), who saw his "absolute idealism" as a completion of the project that Kant had begun, and who grasped the implications of the fact that the peace that has been known to human reason has never been anything but a peace-to-come.

\section{References}

Althusser, L. (2005). For Marx (B. Brewster, Trans.). Verso.

Althusser, L., \& Balibar, É. (1970). Reading Capital (B. Brewster, Trans.). New Left Books.

Dennett, D. C. (1989). The Intentional Stance. Bradford.

Dews, P. (1994). Althusser, Structuralism, and the French Epistemological Tradition. In G. Elliott (Ed.), Althusser: A Critical Reader (pp. 104-141). Blackwell.

Elliott, G. (2006). Althusser: The Detour of Theory (2nd ed.). Brill.

Fink, B. (1996). The Lacanian Subject. Princeton University Press.

Grier, M. (2001). Kant's Doctrine of Transcendental Illusion (1st ed.). Cambridge University Press.

Guyer, P. (2003). Kant on the Systematicity of Nature: Two Puzzles. History of Philosophy Quarterly, 20(3), 277-295.

Guyer, P. (2005). Kant's System of Nature and Freedom: Selected Essays. Oxford University Press.

Hegel, G. W. F. (1979). Phenomenology of Spirit (A. V. Miller, Trans.). Oxford University Press.

Kant, I. (1999). Critique of Pure Reason (P. Guyer, Trans.). Cambridge University Press.

Meillassoux, Q. (2010). After Finitude: An Essay on the Necessity of Contingency (R. Brassier, Trans.). Continuum.

Neiman, S. (1997). The Unity of Reason: Rereading Kant. Oxford University Press.

Pinkard, T. P. (2002). German Philosophy, 1760-1860: The legacy of idealism. Cambridge University Press.

Sandkaulen, B. (2012). Hegel's Post-Metaphysical Thinking. Archives de Philosophie, Volume 75(2), 253-265.

Stavrakakis, Y. (2007). The Lacanian Left: Psychoanalysis, Theory, Politics. State University of New York Press.

Wartenberg, T. (1992). Reason and the Practice of Science. In P. Guyer (Ed.), The Cambridge Companion to Kant (pp. 228-248). Cambridge University Press.

Willaschek, M. (2018). Kant on the Sources of Metaphysics: The Dialectic of Pure Reason. Cambridge University Press. 